\title{
Effects of Perceived Job Insecurity on Perceived Anxiety and Depression in Nurses
}

\author{
Fatma Özyaman BOYA ${ }^{1}$, Yücel DEMIRAL ${ }^{2 *}$, Alp ERGÖR ${ }^{2}$, \\ Yıldız AKVARDAR ${ }^{3}$ and Hans De WITTE ${ }^{4}$
}

\author{
${ }^{1}$ Konak Health District, 35350 Izmir, Turkey \\ ${ }^{2}$ Dokuz Eylül University Medical Faculty, Department of Public Health, 35340 Innciraltı, Izmir, Turkey \\ ${ }^{3}$ Dokuz Eylül University Medical Faculty, Department of Psychiatry, 35340 Înciralt1, Izmir, Turkey \\ ${ }^{4}$ Work Psychology Research Group Work, Organisational and Personnel Psychology (WOPP), Department of \\ Psychology-K.U. Leuven, Tiensestr. 102, Postbox 3725, 3000 Leuven, Belgium
}

Received April 17, 2008 and accepted July 17, 2008

\begin{abstract}
Dramatic changes in workplace structure and environment have increased the importance of psychosocial factors and job insecurity in working life. Job insecurity is shown to have a negative impact on mental and physical health. Health care transformation in Turkey increases the threat of job insecurity for many workers in the health care sector. Therefore the aim of this cross-sectional study was to determine the effects of perceived job insecurity on perceived depression and anxiety in nurses working in the private health sector in Izmir, Turkey. There were 16 private hospitals in Izmir of which 11 accepted to participate. Perceived quantitative (5 items) and qualitative (4 items) job insecurity were measured by means of structured questionnaires. The hospital anxiety and depression scale was used to evaluate subjective anxiety and depression. Job strain was assessed by the Demand-Control-Support Questionnaire. $\chi^{2}$ and logistic regression tests were used for analysis. A total number of 462 nurses were surveyed. Perceived anxiety (OR: 2.2, 95\% CI: 1.2-3.9) and depression (OR: 2.5, 95\% CI: 1.6-4.1) were significantly associated with qualitative job insecurity. Similarly quantitative job insecurity was associated with perceived anxiety (OR: 3.4, 95\% CI: 1.9-6.2) and depression (OR: 2.2, 95\% CI: 1.4-5.6) in nurses. It has been concluded that qualitative and quantitative job insecurity significantly affected perceived anxiety and depression levels in nurses working in private hospitals. Prevention oriented research is needed for policy development.
\end{abstract}

Key words: Perceived job insecurity, Nurse, Perceived anxiety, Depression

\section{Introduction}

There are numerous studies analyzing unemployment and psychological effects related with work. Studies indicate that job loss and unemployment effect well-being ${ }^{1-3)}$. Job insecurity is a status between job and unemployment. It relates to the threat of job loss experienced by the employed $^{1)}$.

Job insecurity can be described in qualitative and quantitative terms. Quantitative job insecurity refers to an overall concern about the continued existence of the job in the future ${ }^{1,4)}$. Qualitative job insecurity refers to per-

*To whom correspondence should be addressed.

E-mail: yucel.demiral@deu.edu.tr ceived threats of impaired quality in the employment relationship, such as a reduction in income, lack of career opportunities and deterioration of working conditions ${ }^{5}$.

Job insecurity is often found to be higher among private sector rather than public workers ${ }^{6,7)}$. In Turkey, health services are predominantly part of the public sector. On the other hand, a fundamental transformation is taking place for fifteen years, the so called "health care reforms". The main feature of this transformation is the establishment of a new model in which the private sector gradually becomes the dominant sector for offering health care by means of market conditions ${ }^{8}$. Even though job insecurity is not a new concept in Turkey, this transformation increases the threat of job insecurity for many workers in the health care sector. Because of downsiz- 
ing in the public sector, more nurses started to introduce more than before to the way of working and thinking in the private sector in which market economy and rivalry reign inherently. This, in turn, makes nurses face job insecurity more often in comparison to previous years. According to 2004 official data, $23 \%$ of all hospitals were private hospitals and 7,357 (17\%) of all nurses work in private health organizations ${ }^{9)}$. Practices customary related with market economy, such as contract employment and performance assessment, are increasingly being introduced into the health care services. The increase of inappropriate employment conditions, including job insecurity, has increased the importance of psychosocial factors ${ }^{10)}$. Job insecurity is shown to have a negative impact on mental and physical health ${ }^{11)}$. Studies have also shown that higher job insecurity is associated with sleep disorders $^{12)}$, anxiety ${ }^{7,11)}$, depression ${ }^{7,13)}$, psycho-somatic complaints related with stress ${ }^{7,14)}$, problems in family relations and diminishing of motivation ${ }^{15}$, poor health ${ }^{11)}$, fatigue and job dissatisfaction ${ }^{11)}$.

The aim of this study was to determine the effects of the perception of job insecurity on anxiety and depression levels among nurses working in private hospitals in Izmir.

\section{Subjects and Methods}

Nurses working in private hospitals were the study group of this cross-sectional study. The study was performed between 12.02.2005-23.5.2005. At the time of the study period 721 nurses were working in 16 private hospitals in Izmir. Four private hospitals did not accept to participate in this research. One of the hospitals was not operational for a year because of construction works. The remaining eleven hospitals accepted to carry out the study. The total number of nurses and the permission of study were taken from the hospital's management. In all, 478 nurses were aimed to recruit into the study. Note however, that three nurses were dismissed after delivery, one nurse was assigned to another institution for educational purposes, nine have refused to participate, and two nurses were also working in public hospitals and were excluded from this study. A total number of 462 nurses out of 478 (97\%) participated in our study. This means that $64 \%$ of all nurses working in private hospitals in Izmir, were reached. The group of nurses gathered in a relevant meeting room before shifts, and informed consent was obtained from all participants before the administration of the questionnaires. Questionnaires were handed out and collected afterwards. The nurses completed all items in the questionnaires. If the nurses were absent at the given date for data collection at least two consecutive visits were performed for each nurse. Since we aimed to plan consecutive visits to reach as many as pos- sible participants, the names were taken to find who was absent in previous visits. Ethical approval of the study is obtained from the Dokuz Eylül Faculty of Medicine Clinical Research Ethics Committee.

Perceived anxiety and depression levels are the dependent variables in this study. Demographic features, employment variables, economical status, work stress, private-life issues for the last fifteen days, perceived job insecurity and habits are the independent variables. Work stress and private-life events for the last fifteen days are evaluated as confounding factors.

The hospital anxiety and depression scale (HAD) developed by Zigmond and Snaith $(1983)^{16,17)}$ was used to measure the level and severity of anxiety and depression. The scale includes seven anxiety and seven depression items. The responses on each item are obtained on a four point Likert scale. The sum of all items indicates the level of depression and anxiety. The cut-off point for anxiety is 10 , and that for depression is 7 in the Turkish version. A score above this point indicates a risk for anxiety or depression. For the Turkish form, the Cronbach alpha coefficient for the anxiety and depression scale is 0.88 and 0.78 , respectively.

Age, gender, marital status, having children, and educational status are socio-demographic variables. Age is a constant variable, and marital status is grouped as single or married. The presence of children is grouped as none versus the number of children. Educational status is grouped into vocational school, two-year high-school, university and post-graduate schooling.

Variables related with working-life are: working-hours, employment status, work duration, secondary work status and union membership. Working hours is coded as the total amount of weekly hours worked. Employment status is grouped as full-time versus part-time. Since the direct data were not available for the turnover rate of the hospitals, work duration in years spent in the present hospital was recorded as proxy measure. Secondary job choices are coded as yes versus no; and the job title is registered. Union membership response choices are member versus non-member.

Economical status is recorded in terms of personal monthly income. Two measures of job insecurity are used. Quantitative job insecurity is measured with 5 items, based on items developed by Ashford et al. (1989), Hellgren et al. (1999), and De Witte (2000). The following items were used to measure quantitative job insecurity:

1. I am afraid I will get fired

2. I worry about keeping my job

3. I fear I will lose my job

4. I think I might get fired in the near future

5. I am sure I can keep my job

This scale has already been tested in a European project 
(Belgium, Italy, the Netherlands and Sweden) ${ }^{18)}$. Qualitative job insecurity was measured with 4 items, based on a scale developed by Isaksson, Hellgren and Pettersson $(1998)^{19)}$.

Items for qualitative job insecurity were as follows:

1. My future career opportunities in [the organization] are favorable

2. I feel that [the organization] can provide me with a stimulating job content in the near future

3. I believe that [the organization] will need my competence also in the future

4. My pay development in this organization is promising These items reflect the definition of Greenhalgh and Rosenblatt (1984) and refer to the threat to the continuity of important job features ${ }^{5}$. Responses are scored on a five-point Likert scale in the original form. In this study, a four-point scale was used (the alternative 'I am not sure' was removed to avoid ambiguity). A high score indicates high job insecurity. The lowest and highest scores for quantitative job insecurity are 5-20. For qualitative job insecurity, these scores are 4-16 respectively. Both scales were pre-tested among 37 health care workers (doctors, nurses, and midwives) in two primary health care units. The reliability coefficient $\alpha$ for qualitative job insecurity is 0.83 . For quantitative job insecurity, this coefficient is 0.73 . Cut-off points for the qualitative and quantitative job insecurity scales are determined according to the median values ( 7 for qualitative job insecurity and 9 for quantitative job insecurity) of the respective scales.

The Turkish version of the Swedish job demand-control-support scale is used to measure work stress ${ }^{20)}$. The scale contains 17 items. Response choices on a 4-point scale are frequently, sometimes, rarely and never. The scale includes items about job demands, job control and social support. A sum score is calculated for every subdimension and the ratio of job demand to job control is defined as job strain. The ratio of strain and social support is used for the evaluation of lack of social support combined with high job strain (iso-strain).

Private life events, such as illness or the loss of a relative in the last fifteen days, are recorded. Smoking is coded as cigarettes per day for the current smokers. If one quitted smoking cigarettes, the non smoking period was recorded.

For statistical analyses, the SPSS 11.0 program is used. $\chi^{2}$ tests are used to determine the significance between groups in bivariate analyses. Logistic regression models were subsequently constructed with the significant variables affecting depression and anxiety levels. In the model which has been composed for anxiety; age, sex and iso-strain, private life events in the last fifteen days, and qualitative and quantitative job insecurity were included. The $\chi^{2}$ analyses show that anxiety levels for respondents under $28 \mathrm{yr}$ old and respondents without children were significantly higher. Because the presence of children is related to age, child presence was not included in the models. In the $\chi^{2}$ analyses, depression levels for nurses whose working duration was under one year were found to be significantly higher. This effect disappears, however, when adjusted for age. Therefore, working duration was not included in the model for depression. Results included the Odds ratios and $95 \%$ confidence intervals. Significance level was determined for $p$ values less than 0.05 .

\section{Results}

The mean age of the study group was $27.7 \pm 7.3$ (range between 19 and 57). Most of the study group were women (93.1\%), 52.2\% graduated from vocational school, $53.9 \%$ were single, and $64.9 \%$ had no child (Table 1 ).

Table 1. Socio-demographic and working life characteristics of the study population

\begin{tabular}{|c|c|c|}
\hline & $\mathrm{n}$ & $\%$ \\
\hline Age $($ mean $\pm \mathrm{SD})$ & \multicolumn{2}{|c|}{$27.7 \pm 7.3$} \\
\hline \multicolumn{3}{|l|}{ Gender } \\
\hline Male & 32 & 6.9 \\
\hline Female & 430 & 93.1 \\
\hline \multicolumn{3}{|l|}{ Graduation } \\
\hline Vocational school & 241 & 52.2 \\
\hline University & 221 & 47.8 \\
\hline \multicolumn{3}{|l|}{ Marital status } \\
\hline Single & 249 & 53.9 \\
\hline Married & 213 & 46.1 \\
\hline \multicolumn{3}{|l|}{ Children } \\
\hline No & 300 & 64.9 \\
\hline Yes & 162 & 35.1 \\
\hline \multicolumn{3}{|l|}{ Work duration (yr) } \\
\hline$<1$ & 146 & 31.6 \\
\hline$\geq 1$ & 316 & 68.4 \\
\hline \multicolumn{3}{|l|}{ Union membership } \\
\hline Non-member & 455 & 98.0 \\
\hline Member & 7 & 2.0 \\
\hline \multicolumn{3}{|l|}{ Shift work } \\
\hline No & 303 & 65.6 \\
\hline Yes & 159 & 34.4 \\
\hline \multicolumn{3}{|l|}{ Night work } \\
\hline No & 131 & 28.4 \\
\hline Yes & 331 & 71.6 \\
\hline \multicolumn{3}{|l|}{ Overtime work } \\
\hline No & 128 & 27.7 \\
\hline Yes & 334 & 72.3 \\
\hline Total & 462 & 100.0 \\
\hline
\end{tabular}


Working life characteristics were as follows: $31.6 \%$ of the nurses had worked less than one year, $2.0 \%$ of the workers were member of a union, $34.4 \%$ were involved in shift work, $71.6 \%$ worked in night work and $72.3 \%$ worked overtime (Table 1).

Bivariate analyses of the association of the socio-demographic variables with anxiety and depression are shown in Tables 2 and 3. Perceived anxiety levels were significantly higher in the group below $28 \mathrm{yr}(p=0.002)$, and among nurses without children, compared to those with

Table 2. Associations of socio-demographic characteristics with perceived anxiety and depression

\begin{tabular}{|c|c|c|c|c|c|}
\hline \multirow{2}{*}{$\begin{array}{l}\text { Socio-demographic } \\
\text { Characteristics }\end{array}$} & \multirow{2}{*}{$\mathrm{n}$} & \multicolumn{2}{|c|}{ Depression } & \multicolumn{2}{|c|}{ Anxiety } \\
\hline & & $\%$ & $p$ & $\%$ & $p$ \\
\hline \multicolumn{6}{|l|}{ Age (yr) } \\
\hline$<28$ & 335 & 31.6 & \multirow{2}{*}{0.07} & 21.8 & \multirow{2}{*}{0.002} \\
\hline$\geq 28$ & 127 & 22.0 & & 9.4 & \\
\hline \multicolumn{6}{|l|}{ Gender } \\
\hline Male & 32 & 21.9 & \multirow{2}{*}{0.36} & 6.3 & \multirow{2}{*}{0.06} \\
\hline Female & 430 & 29.5 & & 19.3 & \\
\hline \multicolumn{6}{|l|}{ Graduation } \\
\hline Vocational school & 241 & 31.1 & \multirow{2}{*}{0.30} & 20.7 & \multirow{2}{*}{0.17} \\
\hline University & 221 & 26.7 & & 15.8 & \\
\hline \multicolumn{6}{|l|}{ Marital status } \\
\hline Single & 249 & 31.7 & \multirow{2}{*}{0.16} & 22.9 & \multirow{2}{*}{0.07} \\
\hline Married & 213 & 25.8 & & 13.1 & \\
\hline \multicolumn{6}{|l|}{ Children } \\
\hline No & 300 & 31.3 & \multirow{2}{*}{0.13} & 22.3 & \multirow{2}{*}{0.003} \\
\hline Yes & 162 & 24.7 & & 11.1 & \\
\hline \multicolumn{6}{|c|}{$\begin{array}{l}\text { Experienced of life events } \\
\text { (last } 15 \text { days) }\end{array}$} \\
\hline Yes & 59 & 54.2 & \multirow{2}{*}{$<0.001$} & 33.9 & \multirow{2}{*}{0.002} \\
\hline No & 403 & 25.3 & & 16.1 & \\
\hline
\end{tabular}

children $(p=0.003)$. Experienced life events in the preceding $15 \mathrm{~d}$ were found to be significantly associated with anxiety $(p=0.002)$ and depression $(p<0.001)$ (Table 2$)$.

Income, union membership, night work and working overtime were not significantly associated with anxiety or depression. The depression levels of the group working for less than one year were significantly higher than those working one year and more $(p=0.03)$ (Table 3).

Qualitative and quantitative perceived job insecurity were significantly associated with perceived anxiety and depression $(p<0.001$ for both comparisons) (Table 4). Perceived depression and anxiety were more common among nurses with high iso-strain $(p<0.001$ and $p=0.003$,

Table 3. Associations of working life characteristics with perceived anxiety and depression

\begin{tabular}{|c|c|c|c|c|c|}
\hline \multirow{2}{*}{ Working life characteristics } & \multirow{2}{*}{$\mathrm{n}$} & \multicolumn{2}{|c|}{ Depression } & \multicolumn{2}{|c|}{ Anxiety } \\
\hline & & $\%$ & $p$ & $\%$ & $p$ \\
\hline \multicolumn{6}{|l|}{ Monthly Salary (USD)* } \\
\hline $325-487$ & 176 & 35.2 & \multirow{3}{*}{0.30} & 22.7 & \multirow{3}{*}{0.96} \\
\hline $488-650$ & 70 & 41.4 & & 24.3 & \\
\hline 651 and over & 44 & 27.3 & & 22.7 & \\
\hline \multicolumn{6}{|l|}{ Work duration (yr) } \\
\hline$<1$ & 146 & 35.6 & \multirow{2}{*}{0.03} & 21.9 & \multirow{2}{*}{0.18} \\
\hline$\geq 1$ & 316 & 25.9 & & 16.8 & \\
\hline \multicolumn{6}{|l|}{ Union membership } \\
\hline No & 455 & 28.8 & \multirow{2}{*}{0.42} & 18.5 & \multirow{2}{*}{0.77} \\
\hline Yes & 7 & 42.9 & & 14.3 & \\
\hline \multicolumn{6}{|l|}{ Night work } \\
\hline No & 131 & 31.3 & \multirow{2}{*}{0.49} & 16.0 & \multirow{2}{*}{0.41} \\
\hline Yes & 331 & 28.1 & & 19.3 & \\
\hline \multicolumn{6}{|l|}{ Overtime work } \\
\hline No & 128 & 28.9 & \multirow{2}{*}{0.98} & 15.6 & \multirow{2}{*}{0.34} \\
\hline Yes & 334 & 29.0 & & 19.5 & \\
\hline
\end{tabular}

Table 4. Associations of perceived job insecurity and Iso-strain with perceived anxiety and depression

\begin{tabular}{lcccccc}
\hline & \multicolumn{3}{c}{ Depression } & \multicolumn{3}{c}{ Anxiety } \\
\cline { 2 - 7 } & $\mathrm{n}$ & $\%$ & $p$ & $\mathrm{n}$ & $\%$ & $p$ \\
\hline Quantitative job insecurity & & & & & & \\
High (n=243) & 96 & 39.5 & & 68 & 28.0 & \\
Low (n=219) & 38 & 17.4 & $<0.001$ & 17 & 7.8 & $<0.001$ \\
\hline Qualitative job insecurity & & & & & & \\
High (n=229) & 97 & 42.4 & & 63 & 27.5 & \\
Low (n=233) & 37 & 15.9 & $<0.001$ & 22 & 9.4 & $<0.001$ \\
\hline Iso-strain & & & & & & \\
Low (n=230) & 47 & 20.4 & & 30 & 13.0 & 0.003 \\
High (n=232) & 87 & 37.5 & $<0.001$ & 55 & 23.7 & \\
\hline
\end{tabular}


Table 5. Results of a logistic regression analysis for perceived anxiety

\begin{tabular}{lcccl}
\hline Variables & $\beta$ & $p$ & OR & $95 \% \mathrm{CI}$ \\
\hline Age (cont.) & -0.024 & 0.231 & 0.98 & $0.94-1.02$ \\
Gender (women) & 1.329 & 0.079 & 3.78 & $0.86-16.60$ \\
Iso-strain (high) & 0.250 & 0.371 & 1.28 & $0.74-2.22$ \\
Life events (yes) & 0.728 & 0.030 & 2.07 & $1.07-3.99$ \\
Qualitative job insecurity (high) & 0.764 & 0.011 & 2.15 & $1.19-3.87$ \\
Quantitative job insecurity (high) & 1.225 & 0.000 & 3.40 & $1.87-6.21$ \\
\hline
\end{tabular}

Table 6. Results of a logistic regression analysis for perceived depression

\begin{tabular}{lcccc}
\hline Variables & $\beta$ & $p$ & OR & $95 \%$ CI \\
\hline Age (cont.) & -0.002 & 0.916 & 1.00 & $0.97-1.03$ \\
Gender (women) & 0.378 & 0.415 & 1.46 & $0.59-3.62$ \\
Iso-strain (high) & 0.401 & 0.089 & 1.49 & $0.94-2.37$ \\
Life events (yes) & 1.073 & 0.001 & 2.92 & $1.60-5.34$ \\
Quantitative job insecurity (high) & 0.804 & 0.000 & 2.23 & $1.39-5.59$ \\
Qualitative job insecurity (high) & 0.921 & 0.004 & 2.51 & $1.55-4.08$ \\
\hline
\end{tabular}

respectively) (Table 4).

Compared with quantitatively secure nurses, insecure nurses had a significant odds ratio of 3.40 (95\% CI: 1.87-6.21) for perceived anxiety. Similarly, qualitative perceived job insecurity was also significantly associated with perceived anxiety (OR: 2.15, 95\%CI: 1.19-3.87). The nurses who experienced life events in the last $15 \mathrm{~d}$ had 2.07 times (95\% CI: 1.07-3.99) more perceived anxiety than those who did not experience such life events. Age, gender, and iso-strain were not significantly associated with perceived anxiety levels (Table 5).

Perceived depression was significantly higher among the qualitatively (OR: $2.51,95 \%$ CI: $1.55-4.08)$ and quantitatively (OR: 2.23 , 95\% CI: 1.39-5.59) insecure nurses. The odds ratio for depression in the nurses who experienced life events in the last $15 \mathrm{~d}$ was 2.92 (95\% CI: 1.60-5.34). Age, gender, and iso-strain were not associated with depression (Table 6).

\section{Discussion}

Jobs in the health care sector are considered as one of the most dangerous jobs with its variety of classical hazardous exposures such as needle stick injuries, chemical, ergonomic factors and organizational risks such as temporary work, outsourcing, shift and night work ${ }^{21)}$. It has been reported that the absenteeism rates, work related illhealth, and early retirement are comparatively high, especially among the nursing staff ${ }^{22}$. This study showed that the perception of quantitative and qualitative job insecurity is associated with perceived anxiety and perceived depression among nurses working in private hospitals in the Izmir metropolis.

Several studies reported similar findings. The Belgian Bellstress study was based on thirteen industries, six bank and insurance companies, four management units, two hospitals, with a total of twenty-five organizations ${ }^{11)}$. In this study, the perception of high levels of quantitative job insecurity was associated with depression for both gender groups. This association was stronger among men $^{11)}$. In the Australian study 'work and health in a contemporary society', professions were grouped according to an Australian standard professional classification. Managers, teachers, nurses, and doctors between 40 and $44 \mathrm{yr}$ old were included. This study shows that work stress and job insecurity are different concepts, and that both have independent negative effects on mental health ${ }^{23)}$. Independently from work stress, the perception of high job insecurity increased the risk of depression with factor four (OR: 3.49, 95\% CI: 1.90-6.41) and three times for anxiety (OR: $3.15,95 \% \mathrm{CI}$ : 1.48-6.70). Even moderate job insecurity was associated with an increased risk of perceived depression and anxiety. High work stress was also independently associated with perceived depression and anxiety (OR: $2.54,95 \% \mathrm{CI}$ : $1.35-4.75$ and 3.15 , 95\%CI: $1.48-6.70$, respectively) ${ }^{23)}$. Studies of plant closures also show that job insecurity (and the threat of job loss) increase anxiety, depression and psychological disorders $^{24)}$. A Danish work environment cohort study, carried out on 4,133 workers, suggested that job insecurity is a determinant of depression in men (RR: 2.04 ; $95 \%$ CI: 1.02-4.07). Job insecurity is however also associated with an increase in depression symptoms (1.2 times higher) in women ${ }^{25}$. The Whitehall II study has also demon- 
strated that chronic perception of job insecurity is associated with depression ${ }^{26)}$.

This study among nurses corroborates those previous studies. In this study, the perception of job insecurity is associated with increased levels of anxiety and depression. The confidence intervals of this study are comparatively narrow.

This study has a number of advantages compared to previous studies in this field. The response rate of this study was very high. Despite factors like shift and night work, working in operating rooms and transportation difficulties, the response rate was no less than $97 \%$ for the study-accepting hospitals. The fact that this study is the first study held among nurses working in the private sector is also a strength of this study. Most studies on this topic measure the perception of job insecurity with only one item. In this study, both qualitative and quantitative job insecurity were measured, and both measures comprised several items validated in previous research. Only a small number of studies differentiated anxiety and depression. This study has analyzed the link between job insecurity and psycho-social work factors with both anxiety and depression. Most studies use a more general mental health assessment or focus on only one component of mental health, such as depression.

The main limitation of this study is its cross-sectional design. In a cross sectional study, the dependent ('causes') and independent ('consequences') variables are measured at the same time, which hampers the determination of causality. The questionnaires were filled out by the participants under supervision. A face to face interview technique was not used. For the reasons the nurses work in the private sector and it was difficult to detain them from work, and in order avoid the nurses influencing each other, the authors decided to use self-administered questionnaires.

Since the questionnaires could not be collected anonymously, the nurses may have been reluctant to rate high on job insecurity. This may cause information bias to some extent. On the other hand there is no reason to differentiate among the respective groups with regard to depression and anxiety levels that suggested the bias towards the null. Finally, this study was carried out in hospitals only in which management agreed to participate. Nurses working in other hospitals could not be reached, which hampers the possibility to generalize our findings.

This research reveals that the perception of job insecurity is associated with depression and anxiety among nurses. High levels of perceived depression and perceived anxiety among nurses may have some negative consequences in a hospital management, patient care and interpersonal relationships. With this regard, implementing flexible job contracts and competing market rules in health care services may cause an increase in the perception of insecurity and also mental health problems. Therefore, the risk should not be considered as an individual problem of the health care workers but as a problem threatening public health. Health care policies and organizations in occupational health services in hospitals may play a crucial role in this context. For example, instead of implementing competing and performance based policies, encouragement of social support and solidarity may prevent insecurity perceptions among health care workers. Regarding the occupational health services, surveillance of the perception of job insecurity provides detailed information to develop policies.

This study is the first applied to nurses working in private hospitals in Turkey. The results are obtained during a period of changes in the health care system in Turkey. As a consequence, the results of this study may reflect a period of transition, in which insecurity prevails.

\section{Conclusion}

Qualitative and quantitative perceived job insecurity are significantly related to perceived anxiety and depression in nurses working in private hospitals. Prevention oriented studies are needed for policy development.

\section{References}

1) De Witte $H$ (2005) Job insecurity: review of the international literature on definitions, prevalence, antecedents and consequences. S Afr J Ind Psychol 31, 1-6.

2) Domenighetti G, D’Avanzo B, Bisig B (2000) Health effect of job insecurity among employees in the Swiss general population. Int J Health Serv 30, 477-90.

3) Lee S, Colditz GA, Berkman LF, Kawachi I (2004) Prospective study of job insecurity and coronary heart disease in US women. Ann Epidemiol 14, 24-30.

4) De Witte H (1999) Job insecurity and psychological well-being: review of the literature and exploration of some unresolved issues. Eur J Work Organ Psychol 8, 155-77.

5) Hellgren J, Sverke M, Isaksson K (1999) A two-dimensional approach to job insecurity: consequences for employee attitudes and well-being. Eur J Work Organ Psychol 8, 179-95.

6) Vandoorne J, De Witte H (2002) In het ongewisse. Over het voorkomen en de gevolgen van jobonzekerheid in Vlaanderen. (On the prevalence and consequences of job insecurity in Flanders) In: Vandenbroucke, G (Red.), Arbeidsmarktonderzoekersdag 2001. Verslagboek. WAV Dossier. Leuven: steunpunt Werkgelegenheid, Arbeid en Vorming, 135-51.

7) Mauno S, Kinnunen U (2002) Perceived job insecurity among dual-earner couples: do its antecedents vary according to gender, economic sector and the measure 
used? J Occup Organ Psychol 75, 295-314.

8) Demiral Y, Akvardar Y, Ergör A, Ergör G (2006) The impact of job satisfaction on anxiety and depression levels among universty physicians. J Dokuz Eylul Medical Faculty 20, 157-64 (in Turkish).

9) Distribution of hospitals according to organizations in Turkey.Yataklı Tedavi Kurumları İstatistik Yıllı̆̆ 2004. http://www.saglik.gov.tr/extras/istatistikler. Accessed April 25, 2006 (in Turkish).

10) Demiral Y (2004) Psychosocial work environment. Turk J Occup Health Saf 20, 22-6 (in Turkish).

11) Pelfrene E, Vlerick P, Moreau M, Mak RP, Kornitzer M, De Backer G (2003) Perceptions of job insecurity and the impact of world market competition as health risks: results from bellstress. J Occup Organ Psychol 76, 411-25.

12) Ferrie JE (1999) Health consequences of job insecurity. In: Labour market chances and job insecurity: a chance for social welfare and health promotion. Ferrie JE, Marmot MG, Griffiths J, Ziglio E (Eds.), 59-89, WHO Regional Publications, European Series, No.81., Copenhagen.

13) Büssing A (1999) Can control at work and social support moderate psychological consequences of job insecurity? Results from a quasi-experimental study in the steel industry. Eur J Work Organ Psychol 8, 219-42.

14) Probst TM, Brubaker TY (2001) The effects of job insecurity on employee safety outcomes: cross-sectional and longitudinal explorations. J Occup Health Psychol 6, 139-59.

15) Job insecurity and work intensification. http://www.jrf. org.uk/knowledge/findings/socialpolicy/849.asp. Accessed September 14, 2004.

16) Zigmond S, Snaith RP (1983) The hospital anxiety and depression. scale. Acta Psych Scand 67, 361-70.

17) Aydemir Ö, Güvenir T, Küey L, Kültür S (1997) Validity and reliability of the Turkish version of the hospital anxiety and depression scale. Turk J Psychiatry 8, 280-7.

18) Sverke M, Hellgren J, Näswall K, Chirumbolo A, De
Witte H, Goslinga S (2004) Job insecurity and union membership. European Unions in the wake of flexible production, 202, P.I.E.-Peter Lang, Brussels.

19) Isaksson K, Hellgren J, Pettersson P (1998) Strukturomvandling inom svensk detaljhandel: Uppföljning av omorganisation och personalminskning i KF/KDAB [Structural transformation in Swedish retail trade: Follow-up of a reorganization and layoff in $\mathrm{KF} / \mathrm{KDAB}$. Reports from the Department of Psychology, No. 97/1998. Stockholm University, Stockholm.

20) Demiral Y, Soysal A, Bilgin AC, Kılıc B, Unal B, Ucku $\mathrm{R}$, Theorell $\mathrm{T}$ (2006) The association of job strain with coronary hearth disease and metabolic syndrome in municipality workers in Turkey. J Occup Health 48, 332-8.

21) Hasselhorn HM, Toomingas A, Langerström M (1999) Occupational health for health care workers. A practical Guide. 1st Ed., Elsevier, Amsterdam.

22) Froneberg B (2006) National and international response to occupational hazards in the healthcare sector, Annals NY Acad Sci 1076, 607-14.

23) D'Souza RM, Strazdins L, Lim LL, Broom DH, Rodger SB (2003) Work and health in a contemporary society: demands, control and insecurity. J Epidemiol Community Health 57, 849-54.

24) Ferrie JE, Shipley MJ, Marmot MG, Stansfeld S (1998) The health effects of major organizational change and job insecurity. Soc Sci Med 46, 243-54.

25) Rugulies R, Bültmann U, Aust B, Burr H (2006) Psychosocial work environment and incidence of severe depressive symptoms: prospective findings from a 5year follow-up of the Danish work environment cohort study. Am J Epidemiol 163, 877-87.

26) Ferrie JE, Shipley MJ, Stansfeld SA, Marmot MG (2002) Effect of chronic job insecurity and change in job security on self reported health, minor psychiatric morbidity, physiological measures, and health related behaviours in British civil servants: the Whitehall II study. J Epidemiol Community Health 56, 450-4. 